\title{
Optimization of Chemical Kinetics for Methane and Biomass Pyrolysis Products in Moderate or Intense Low-Oxygen Dilution Combustion
}

\author{
Magnus Fürst, ${ }^{\dagger}, \dagger, \S \odot$ Pino Sabia, " Marco Lubrano Lavadera, ${ }^{\circ}$ Gianmarco Aversano, ${ }^{\dagger, \S, \perp}$
}

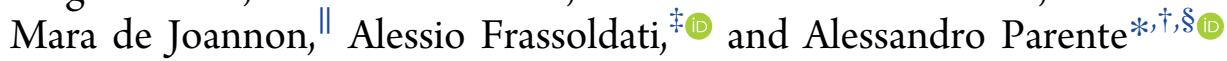

\author{
${ }^{\dagger}$ Université Libre de Bruxelles, Ecole Polytechnique de Bruxelles, Aero-Thermo-Mechanics Laboratory, Avenue Franklin D. \\ Roosevelt 50, CP 165/41, 1050 Brussels, Belgium \\ ${ }^{\ddagger}$ Department of Chemistry, Materials, and Chemical Engineering, Politecnico di Milano, Piazza Leonardo da Vinci 32,20133 \\ Milano, Italy \\ ${ }^{\S}$ Combustion and Robust Optimization Group (BURN), Université Libre de Bruxelles and Vrije Universiteit Brussel, 1050 Bruxelles, \\ Belgium \\ "Istituto di Ricerche sulla Combustione (IRC), Consiglio Nazionale delle Ricerche (CNR), Piazzale Vincenzo Tecchio 80,80125 \\ Naples, Italy \\ ${ }^{\perp}$ Laboratoire EM2C, CNRS, Centrale-Supélec, Université Paris-Saclay, 8-10 rue Joliot-Curie 91190 Gif-sur-Yvette, France
}

Supporting Information

\begin{abstract}
The performance of existing detailed chemical mechanisms with respect to moderate or intense low-oxygen dilution (MILD) combustion is not optimal. The use of optimization procedures can therefore be used to quantify and minimize the uncertainties in chemical mechanisms with respect to available experimental targets in these conditions. This work puts forth a methodology that improves the performance of chemical kinetics with respect to MILD combustion. The experimental data used in this paper are from a plug flow reactor, where the ignition delay time for methane and biomass pyrolysis products in MILD conditions was analyzed. The initial mechanism was then evaluated, and the reactions with the highest impact factors were used in the optimization process. The combination of parameters that gave the lowest error with respect to the experimental data was then determined, and the proposed mechanism performance was improved with respect to the experimental targets.
\end{abstract}

\section{INTRODUCTION}

The future energy demand is constantly increasing at the same time as emission regulations are becoming stricter to reduce the environmental impact from energy production. One of the most flexible technologies to produce energy is through combustion, but to satisfy these criteria, new and more efficient combustion technologies are needed. Moderate or intense lowoxygen dilution (MILD) combustion is one such technology. MILD conditions can be reached by recirculating hot combustion products back toward the fuel stream, thus diluting and preheating the fuel. When the temperature of the fuel stream is above the self-ignition temperature of the fuel and the maximum temperature increase is less than the selfignition temperature of the fuel, MILD conditions are reached. ${ }^{1}$ Under these conditions, the temperature peaks are drastically reduced and, therefore, also the $\mathrm{NO}_{x}$ emissions because of reduced production of thermal $\mathrm{NO}_{x}$ in the combustion process. These conditions also lead to a more homogeneous temperature distribution, where there is no visible flame in the combustion zone, which is why such a regime is often referred to as flameless combustion. ${ }^{2,3}$ These aspects ensure both lower emissions and more efficient combustion, which also allows for unconventional fuels to be used in an efficient way.
The implementation and development of this technology for different applications can be drastically improved using computational fluid dynamics (CFD). CFD is much more time-efficient and more economical compared to more traditional trial and error approaches. With CFD, many different conditions can be tested efficiently to find the optimal configuration for each application.

However, modeling aspects become critical while simulating MILD combustion. As a result of the strong mixing between the fresh reactants and hot combustion products and the lower temperature in these conditions, the mixing time scale is reduced at the same time as the chemical time scale is increased; i.e., these conditions are characterized by low Dahmköler numbers, with respect to conventional combustion. This results in a strong interaction between fluid dynamics and chemistry, thus indicating that a detailed chemical mechanism should be used. The problem that arises from this is that existing detailed chemical mechanisms were all developed and

Special Issue: SMARTCATs COST Action

Received: March 26, 2018

Revised: June 6, 2018

Published: June 8, 2018 
validated in conventional combustion regimes, while their performance for MILD combustion conditions is not optimal.

Recently, Tu et $\mathrm{al}^{4}{ }^{4}$ worked on the optimization of global reaction mechanisms, specifically for MILD combustion. However, they do mention that the prediction of intermediate products, such as $\mathrm{CO}$, is not captured well with these global mechanisms as a result of the absence of radical species, such as $\mathrm{OH}$.

In Sabia et al., ${ }^{5}$ a numerical study showed that existing detailed chemical mechanisms are not accurately predicting the so-called negative temperature coefficient (NTC) region, which is highly influential in MILD conditions. It was also shown in the study by Sabia et al. ${ }^{6}$ that, while the general behavior of a MILD combustion system is predicted with different detailed mechanisms, the moment of ignition differs drastically. This quantity is very important to accurately predict the behavior of MILD regimes, because these conditions rely on a highly distributed ignition process. Further, the modest temperature increments in these conditions emphasize the effects of the uncertainties of the chemical reaction rates, and the performance of the kinetic models is therefore also highly uncertain. To improve the proficiency of chemical mechanisms with respect to MILD combustion, optimization/uncertainty quantification (UQ) can be used to quantify and minimize the uncertainties in the existing chemical mechanism. When uncertainties are prescribed to parameters in the chemical mechanism, the inherent uncertainty in the mechanism can be re-evaluated and a more optimal combination of kinetic parameters can be chosen for the specific conditions. This is often called backward UQ or the inverse problem. ${ }^{7}$ This methodology was applied for the development of the widely used GRI-Mech 3.0 mechanism, ${ }^{8}$ applying the so-called bound-to-bound data collaboration (B2B-DC) approach, ${ }^{9}$ as well as for the development of a mechanism for hydrogen ${ }^{10}$ and syngas combustion. ${ }^{11}$ There have also been some recent work on the optimization of a hydrogen combustion mechanism $^{12}$ and a joint hydrogen and syngas combustion mechanism ${ }^{13}$ using a different methodology described in the study by Turányi et al. ${ }^{14}$

Recently Samu et al. ${ }^{15}$ used the same approach as in the study by Turányi et al. ${ }^{14}$ to optimize a few reactions with respect to specific experimental targets, namely, $\mathrm{NH}_{2}$ concentration profiles in ammonia-doped methane flames. A similar approach was applied for this work, to improve an existing detailed mechanism performance with respect to MILD combustion targets, for which there is no existing literature.

\section{MATERIALS AND METHODS}

The reliability of the optimization procedure increases with the number of experimental data points considered. However, the available data from canonical reactors in MILD conditions and for the range of investigated dilution conditions is quite scarce in the literature. We therefore considered the 50 available data points from Sabia et al. ${ }^{16}$ and Sabia et al., ${ }^{17}$ where the ignition delay time for methane and biomass pyrolysis products in MILD conditions in a plug flow reactor (PFR) was measured. The combination of two different fuel compositions, methane and biomass pyrolysis products, is nevertheless a first step toward the development of a generally applicable mechanism for MILD combustion.

2.1. Experimental Data. The same experimental facility was used in both cases, which consists of a $1.4 \mathrm{~m}$ long tube with an internal diameter of $0.01 \mathrm{~m}$, which was enclosed in a heater to reduce heat loss to the surroundings, and the overall heat transfer coefficient was estimated in the study by Sabia et al. ${ }^{16}$ to be $100.4 \mathrm{~W} \mathrm{~m}^{-2} \mathrm{~K}^{-1}$. A mixture of fuel and air, diluted with nitrogen, was injected at atmospheric pressure at different $\mathrm{C} / \mathrm{O}$ or oxygen ratios $(\Omega)^{18}$ and different inlet temperatures. The use of the oxygen ratio for the biomass pyrolysis product data was due to the presence of partially oxidized compounds in the fuel. A more detailed discussion and description regarding this can be found in the study by either Sabia et al. ${ }^{17}$ or Mueller et al. ${ }^{18}$ The reference composition of the biomass pyrolysis products was $1 \% \mathrm{C}_{2} \mathrm{H}_{4}, 2 \% \mathrm{C}_{2} \mathrm{H}_{6}, 10 \% \mathrm{CH}_{4}, 25 \% \mathrm{CO}$, and $62 \% \mathrm{CO}_{2}$. The nitrogen dilution was $85 \%$ for the methane cases and $90 \%$ for biomass pyrolysis product cases.

In the experiments, the ignition delay time was calculated as the ratio between the distance where the temperature was $10 \mathrm{~K}$ higher than the inlet temperature and the velocity. The same definition was applied in the present work for a direct comparison between the experimental data and the simulation results. The temperature was measured along the reactor axis with thermocouples of type $\mathrm{N}$ every $0.05 \mathrm{~m}$. The experimental uncertainty was estimated on the basis of the displacement of the thermocouples and the inlet velocity of the mixture. ${ }^{16,17}$

The experimental conditions were simulated using the open-source software OpenSMOKE $++{ }^{19,20}$ for non-isothermal and non-adiabatic conditions. According to Sabia et al., ${ }^{16}$ the Reynolds number is higher than 3000 for the experiments, which verifies the plug flow assumption in the model.

2.2. Optimization Procedure. To determine the main parameters for the optimization study, a ranking of the reactions was conducted on the basis of a so-called impact factor. ${ }^{21}$ The impact factor was defined as the absolute value of the local sensitivity coefficient multiplied with the uncertainty parameter $(f)$ for the reaction. This was initially introduced by Warnatz ${ }^{22}$ as a measure to know for which reactions more experimental work is necessary. In this work, it was used instead as an indication of how impactful changing the kinetic parameters of one reaction would be with respect to the quantity of interest (QoI). This impact factor has also been referred to as the "sensitivity uncertainty index" ${ }^{23}$ as well as "optimization potential" ${ }^{24,25}$ in previous studies. The sensitivity coefficient for each reaction ( $i$ ) was calculated as a normalized sensitivity to the temperature with respect to a change in the pre-exponential factor, i.e., $\left(A_{i} / T\right)\left(\mathrm{d} T / \mathrm{d} A_{i}\right),{ }^{26}$ at the exact moment of ignition, for each of the data points. The use of local rather than global sensitivity analysis have been discussed in refs 26 and 27, and also in this work, a local sensitivity analysis was considered sufficient to determine the most influential reactions with respect to the QoI, i.e., the ignition delay time. The uncertainty parameter $f$ is defined as $f=\log _{10}\left(k_{0} / k_{\min }\right)=$ $\log _{10}\left(k_{\max } / k_{0}\right)$, where $k_{0}$ is the standard rate coefficient and $k_{\min }$ and $k_{\max }$ are the minimum and maximum values of the rate coefficient, respectively.

The uncertainty parameters were primarily extracted from the Baulch database ${ }^{28}$ for the 20 reactions with the highest absolute value of the sensitivity coefficients at each data point. However, if the reaction was not listed in the study by Baulch et al., ${ }^{28}$ estimations of the uncertainty parameter based on data from Manion et al. ${ }^{29}$ were made. Considering that, for these reactions, not much data were available, relatively high uncertainty parameters were assumed, i.e., $f \geq$ 0.5 . Although the uncertainty parameter $f$ is a temperature-dependent parameter, it should be noted that, in this work, only the highest value for each reaction was considered.

The uncertainty range of the reaction parameters, i.e., the preexponential factor $(A)$, the temperature exponent $(\beta)$, and the activation energy $(E)$, were then evaluated through the following steps: (a) First only $A$ is considered uncertain, which then corresponds an uncertainty range equal to the extreme curves $k_{\min }$ and $k_{\max }$. (b) If either $\beta$ or $E$ are equal to zero, the range of the second non-zero parameter can simply be determined with the extreme points, $k_{\min }\left(T_{\max }\right)$ with $k_{\max }\left(T_{\min }\right)$ and $k_{\max }\left(T_{\max }\right)$ with $k_{\min }\left(T_{\min }\right)$, where $T_{\min }$ and $T_{\max }$ were taken as a large range $(300-2500 \mathrm{~K})$ to ensure a large validity of the mechanism. (c) Otherwise, the range of $\beta$ is evaluated by fixing $E$ to its nominal value as well as letting $A$ be unknown. Then, using the extreme points defined by the temperature 
range and the maximum and minimum rate coefficient curves, the maximum and minimum $\beta$ values can be found. The range of $A$ determined in this step is not considered, because the range determined in step a is used for this parameter. (d) Finally, the range of $E$ is determined similarly as for $\beta$ in step c, using the extreme points. However, this time, $\beta$ is fixed to its nominal value and $A$ is still considered unknown. Again, the range of $A$ determined in this step is not considered.

An example of this procedure can be seen in Figure 1, where the extreme curves for the rate coefficient for reaction $\mathrm{CH}_{4}+\mathrm{H}=\mathrm{H}_{2}+$ $\mathrm{CH}_{3}$ are plotted as well as the base curve $k_{0}$ and the $k_{\min }$ and $k_{\max }$ curves.

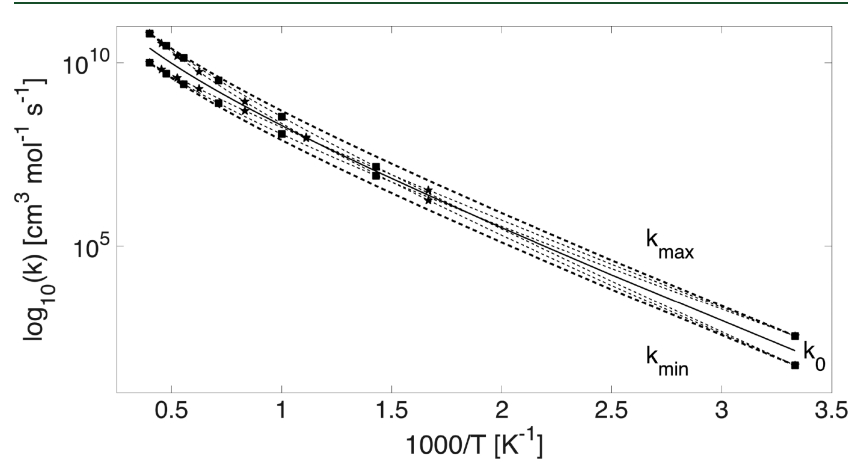

Figure 1. Rate coefficient for reaction $\mathrm{CH}_{4}+\mathrm{H}=\mathrm{H}_{2}+\mathrm{CH}_{3}$, where the solid line corresponds to the nominal curve from the POLIMI $\mathrm{C} 1-\mathrm{C} 3^{30}$ mechanism and the dashed lines correspond to the extreme curves $k_{\min }$ and $k_{\max }$, while the dashed curves with stars correspond to the extreme curves for the temperature exponent $\beta$ and the dashed curves with squares correspond to the extreme curves for the activation energy $E$, derived from the approach described in the text.

This approach is similar to what is described in the study by Nagy et al., ${ }^{31}$ but they recommend using a range for $\beta$ of \pm 2 of the base value. This range was found to be too large for the above-mentioned reaction, which is why this new approach is proposed.

This space of parameters was then sampled using latin hypercube sampling (LHS), which were used to create surrogate models with the help of the Matlab toolbox ooDACE, ${ }^{32,33}$ which uses the so-called Kriging interpolation method. ${ }^{34} \mathrm{~A}$ surrogate model in this aspect refers to a simplified model of the full system for a faster estimation of the model output. One surrogate model was created with respect to each experimental point to reduce interpolation errors with respect to either inlet temperature, $\mathrm{C} / \mathrm{O}$ ratio, or $\Omega$ value. Only some of the initial samples created with LHS were used for the surrogate building, while the rest were used to evaluate the fitting error of the surrogate models, with respect to the total set of samples. Then, rather than adding other random samples to reduce the fitting error, the samples that showed the highest fitting error were added to the surrogate building process in an iterative way until the maximum fitting error reached a converged value strictly lower than $10 \%$. This so-called adaptive sampling procedure reduces the number of samples needed for building the surrogates as well as the size of the initial sample pool needed, including both samples used for building the surrogates and the samples used for evaluating the fitting error. To ensure a good estimation of the fitting error, the total sample pool was at least twice the size of the number of final samples used to build the surrogate models. It should be noted that the size of the sample pool could not be determined a priori; instead, a sufficiently large number of samples was included. For the cases evaluated in this work, a set of 600 samples was initially created and used for the surrogate building and the fitting error evaluation.

The final surrogate models were then used to evaluate several thousands of combinations of the uncertain parameters, to find the optimal combinations of values with respect to the experimental data. However, to ensure that a specific combination of parameters allowed the rate coefficient to stay within its uncertainty limits, an a posteriori evaluation of the kinetic parameter combinations was performed and only the combinations that gave $k$ values within the uncertainty limits were considered.

The use of surrogate models rather than evaluating each possible parameter combination through simulations can drastically reduce the computational costs, considering both storage and calculation time, and is widely adopted in the field of UQ..$^{10,11,13,35-37}$

As a final step, a least squared fit was evaluated, considering the discrepancy between the surrogate model predictions and the experimental data points

$$
S=\sum_{n}\left(d_{n}-M_{n}(\mathbf{X})\right)^{2}
$$

where $S$ is the sum of the square of the residual between the experimental data $(d)$ and model prediction $(M)$, in each point $n$. The combination of the uncertain parameters $\mathbf{X}$ that showed the lowest $S$ can therefore be considered the optimal set of kinetic parameter values for the experimental targets used in this work.

It should be noted that nonlinear optimization problems, such as this, could consists of several local minima of the objective function $S$, and finding the global minimum is difficult. However, using the approach described in this paper ensures that each viable combination within the predetermined uncertainty range was evaluated and compared against each other and, therefore, allows the determination of the optimum out of all of the evaluated parameter combinations.

The primary purpose of the present paper is to show the feasibility of the presented approach, demonstrating it for the MILD combustion of methane and biomass pyrolysis products under high dilution conditions.

\section{RESULTS AND DISCUSSION}

An initial set of simulations with eigth different, well-known, detailed chemical mechanisms showed that the POLIMI C1$\mathrm{C} 3^{30}$ mechanism gave the smallest average error with respect to the experimental targets. The average error was calculated as the absolute difference between the experimental value and the simulation estimation, for each experimental point, divided by the experimental value in that point. In Table 1, the different

Table 1. List of Chemical Mechanism Used in This Work with Reference, Number of Species, Number of Reactions, and Average Absolute Deviation from Experimental Data ${ }^{16}$

\begin{tabular}{lcccc} 
mechanism & reference & $\begin{array}{c}\text { number of } \\
\text { species }\end{array}$ & $\begin{array}{c}\text { number of } \\
\text { reactions }\end{array}$ & $\begin{array}{c}\text { average absolute } \\
\text { deviation (\%) }\end{array}$ \\
Aramco1.3 & 38 & 124 & 766 & 50.06 \\
Aramco2.0 & 39 & 502 & 2716 & 43.97 \\
Galway & 40 & 293 & 1593 & 44.19 \\
GRI2.11 & 41 & 49 & 279 & 67.53 \\
GRI3.0 & 8 & 53 & 325 & 67.86 \\
POLIMI & 30 & 107 & 2642 & 39.66 \\
San Diego & 42 & 57 & 268 & 77.86 \\
Zhukov & 43 & 549 & 2518 & 66.57 \\
\hline
\end{tabular}

mechanisms used can be seen with reference, number of species, number of reactions, and average deviation from the experimental data. The simulation results are presented in Figures $2-7$ in so-called Arrhenius plots, where the ignition delay time is presented in the logarithmic scale on the $y$ axis and the $x$ axis is represented by 1000 divided by the inlet temperature of the mixture. For the methane cases, the $\mathrm{C} / \mathrm{O}$ ratio spans from 0.025 to 0.2 , i.e., fuel-lean conditions, and for the biomass pyrolysis product cases, $\Omega$ is equal to 0.9 and 1 , i.e., fuel-rich and stoichiometric conditions. This ensures that the experimental data overall cover a large range of conditions. 


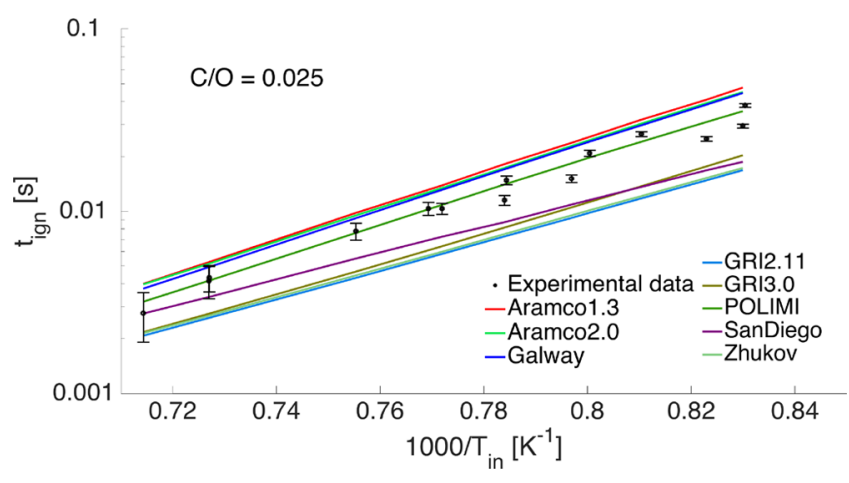

Figure 2. Ignition delay time for methane at different inlet temperatures for $\mathrm{C} / \mathrm{O}=0.025$. Experimental data are represented by points, while simulation results for the different mechanisms are presented by colored lines.

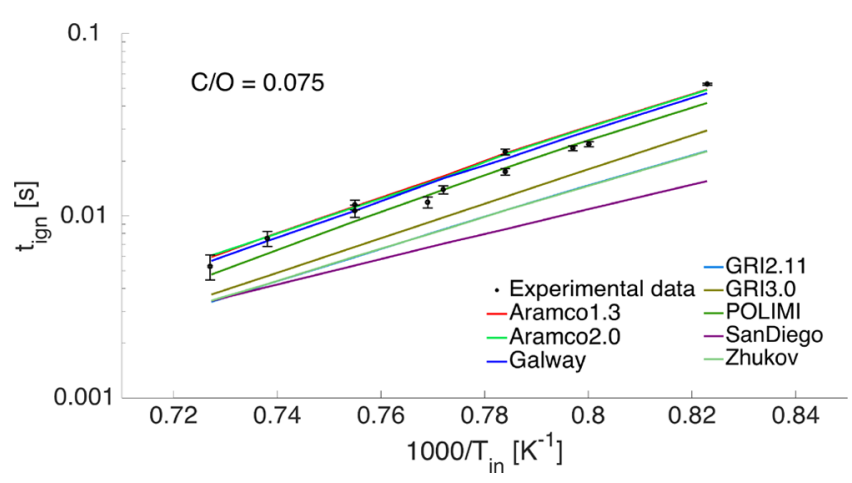

Figure 3. Ignition delay time for methane at different inlet temperatures for $\mathrm{C} / \mathrm{O}=0.075$. Experimental data are represented by points, while simulation results for the different mechanisms are presented by colored lines.

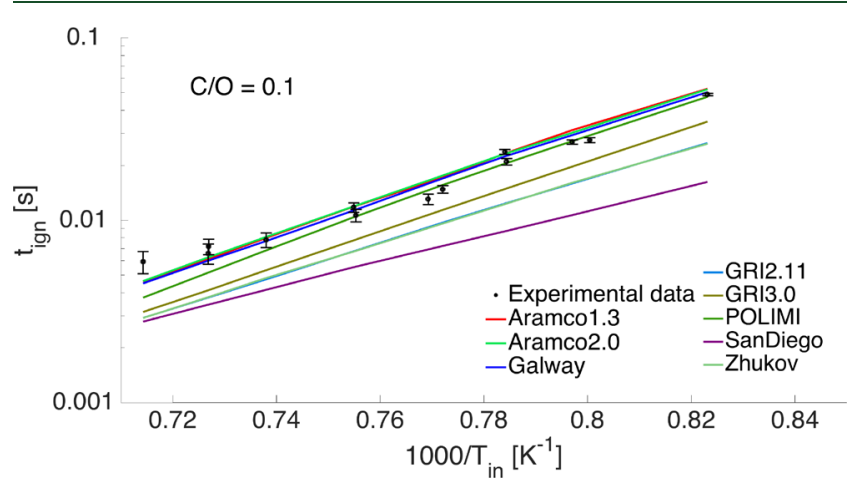

Figure 4. Ignition delay time for methane at different inlet temperatures for $\mathrm{C} / \mathrm{O}=0.1$. Experimental data are represented by points, while simulation results for the different mechanisms are presented by colored lines.

The impact factor analysis resulted in a set of 42 different reactions, which occurred in the top 20 most sensitive reactions for at least one of the simulated conditions. The average impact factor for these reactions can be seen in Figure 8 , where they are also ranked on the basis of this value.

To reduce the number of parameters evaluated in this study, an initial evaluation of the top five reactions was performed, to determine if the prior uncertainty range for each reaction was enough to cover the complete range of the experimental uncertainty. This was performed by evaluating the individual uncertainty of each reaction, propagated with respect to the

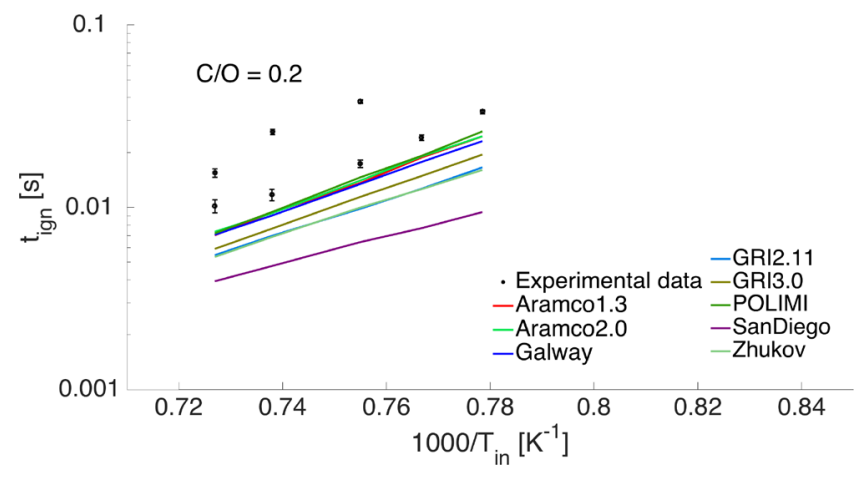

Figure 5. Ignition delay time for methane at different inlet temperatures for $\mathrm{C} / \mathrm{O}=0.2$. Experimental data are represented by points, while simulation results for the different mechanisms are presented by colored lines.

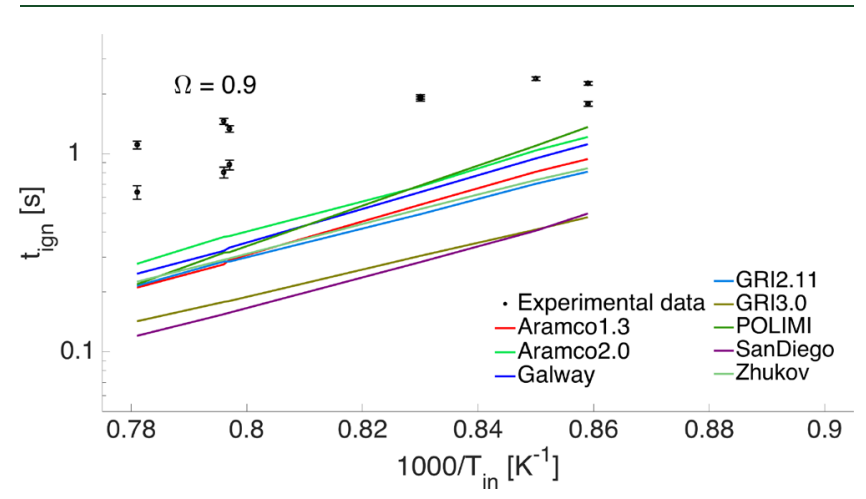

Figure 6. Ignition delay time for biomass pyrolysis products at different inlet temperatures for $\Omega=0.9$. Experimental data are represented by points, while simulation results for the different mechanisms are presented by colored lines.

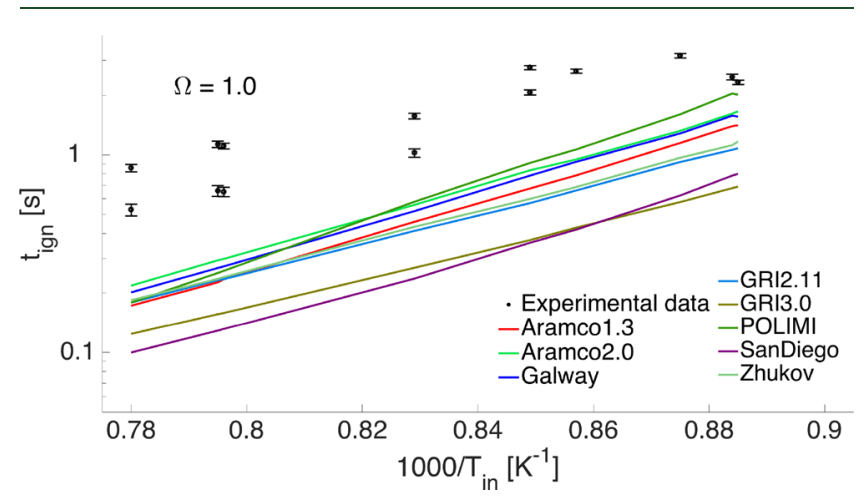

Figure 7. Ignition delay time for biomass pyrolysis products at different inlet temperatures for $\Omega=1.0$. Experimental data are represented by points, while simulation results for the different mechanisms are presented by colored lines.

experimental data. If the prior uncertainty range for a specific reaction was not sufficient enough, that reaction was not considered in the optimization process.

This study showed that reactions $\mathrm{R} 229\left(\mathrm{O}_{2}+\mathrm{CH}_{3}=\mathrm{O}+\right.$ $\left.\mathrm{CH}_{3} \mathrm{O}\right)$ and $\mathrm{R} 513\left(\mathrm{CH}_{3} \mathrm{OO}=\mathrm{CH}_{2} \mathrm{O}+\mathrm{OH}\right)$ had very small impact on the prediction of the ignition delay time, especially for the biomass pyrolysis product cases, even though their global impact factor ranking was high. Reactions $\mathrm{R} 1\left(\mathrm{O}_{2}+\mathrm{H}=\right.$ $\mathrm{O}+\mathrm{OH}), \mathrm{R} 271\left(\mathrm{HO}_{2}+\mathrm{CH}_{3}=\mathrm{OH}+\mathrm{CH}_{3} \mathrm{O}\right)$, and $\mathrm{R} 405$ $\left(\mathrm{CH}_{4}+\mathrm{H}=\mathrm{H}_{2}+\mathrm{CH}_{3}\right)$ on the other hand showed large prior uncertainty ranges on the ignition delay time predictions with 


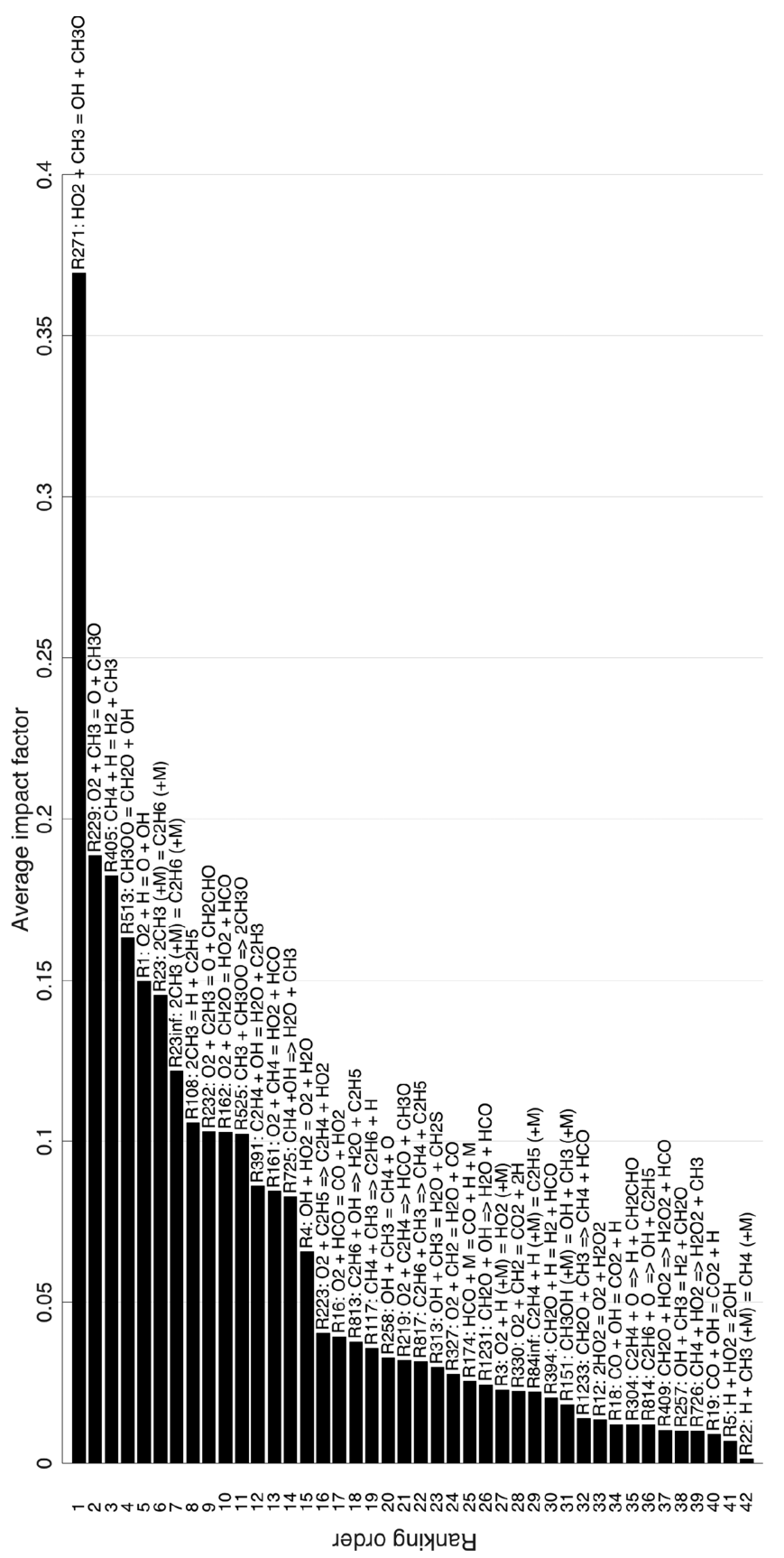

Figure 8. Average impact factor for the 42 reactions, which occurred in the top 20 most sensitive reactions for at least one simulated condition. The reactions are presented in descending order based on this averaged impact factor.

respect to all of the experimental data. The complete evaluation of these reactions can be seen in the Supporting Information.

Reaction $\mathrm{R} 1\left(\mathrm{O}_{2}+\mathrm{H}=\mathrm{O}+\mathrm{OH}\right)$ is indeed very influential in the ignition process because it is a branching reaction, which creates two highly reactive radicals $(\mathrm{O}$ and $\mathrm{OH})$, and although the uncertainty parameter for this reaction is quite low, i.e., $f=$ 0.2 , even small changes to the kinetic parameters have a large impact on the prediction of the ignition delay time.

Reaction $\mathrm{R} 271\left(\mathrm{HO}_{2}+\mathrm{CH}_{3}=\mathrm{OH}+\mathrm{CH}_{3} \mathrm{O}\right)$ is an oxidation route for methyl, and it is also highly influential for the ignition delay time in MILD conditions, which is discussed in the study of Sabia et al. ${ }^{16}$ This reaction consists only of a value for the pre-exponential factor $A$, while the other Arrhenius parameters are zero. The uncertainty parameter $f$ for this reaction is therefore very high, i.e., $f=1$, and, hence, also the impact factor.

Reaction $\mathrm{R} 405\left(\mathrm{CH}_{4}+\mathrm{H}=\mathrm{H}_{2}+\mathrm{CH}_{3}\right)$ is a propagation reaction, which creates the methyl radical, already mentioned before to be highly influential for the ignition delay time in MILD conditions.

The nominal parameter value as well as the minimum and maximum values for these three reaction can be found in Table 2.

Table 2. Uncertain Parameters for Considered Reactions with Nominal Values from the POLIMI C1-C $3^{30}$ Mechanism and Prior Uncertainty Range of Each Parameter $^{a}$

\begin{tabular}{|c|c|c|c|}
\hline kinetic parameter & nominal value & minimum value & maximum value \\
\hline \multicolumn{4}{|c|}{$\mathrm{R} 1\left(\mathrm{O}_{2}+\mathrm{H}=\mathrm{O}+\mathrm{OH}\right)$} \\
\hline$A_{\mathrm{R} 1}$ & $9.6 \times 10^{11}$ & $6.1 \times 10^{11}$ & $1.5 \times 10^{12}$ \\
\hline$\beta_{\mathrm{R} 1}$ & -0.2 & -0.6 & 0.2 \\
\hline$E_{\mathrm{R} 1}$ & 16625 & 16001 & 17249 \\
\hline \multicolumn{4}{|c|}{$\mathrm{R} 271\left(\mathrm{HO}_{2}+\mathrm{CH}_{3}=\mathrm{OH}+\mathrm{CH}_{3} \mathrm{O}\right)$} \\
\hline$A_{\mathrm{R} 271}$ & $6.00 \times 10^{9}$ & $6.00 \times 10^{8}$ & $6.00 \times 10^{10}$ \\
\hline \multicolumn{4}{|c|}{$\mathrm{R} 405\left(\mathrm{CH}_{4}+\mathrm{H}=\mathrm{H}_{2}+\mathrm{CH}_{3}\right)$} \\
\hline$A_{\mathrm{R} 405}$ & $3.0 \times 10^{4}$ & $1.2 \times 10^{4}$ & $7.5 \times 10^{4}$ \\
\hline$\beta_{\mathrm{R} 405}$ & 2.0 & 1.13 & 2.87 \\
\hline$E_{\mathrm{R} 405}$ & 10000 & 8752 & 11248 \\
\hline
\end{tabular}

${ }^{a}$ The units of the different kinetic parameters are as follows: $A\left(\mathrm{~s} \mathrm{~cm}^{3}\right.$ $\mathrm{mol}), \beta$, and $E(\mathrm{cal} / \mathrm{mol})$.

Surrogate models was thereafter built based on these seven parameters, and a large number of valid parameter combinations, namely, 544480 , was evaluated to find the optimal combination.

As mentioned, the criteria for determining the overall optimal mechanism was performed by evaluating the sum of the square of the residual for each surrogate model/ experimental point. The performance of this optimized mechanism, with respect to the nominal POLIMI $\mathrm{C} 1-\mathrm{C} 3^{30}$ mechanism, can be seen in Figures 9-14.

The corresponding parameters for the optimized mechanism are presented in Table 3 as well as the sum of squared residuals $(S)$, calculated using eq 1. For comparison, the nominal POLIMI $\mathrm{C} 1-\mathrm{C}^{30}$ mechanism parameters are also presented in Table 3, together with its calculated sum of squared residual.

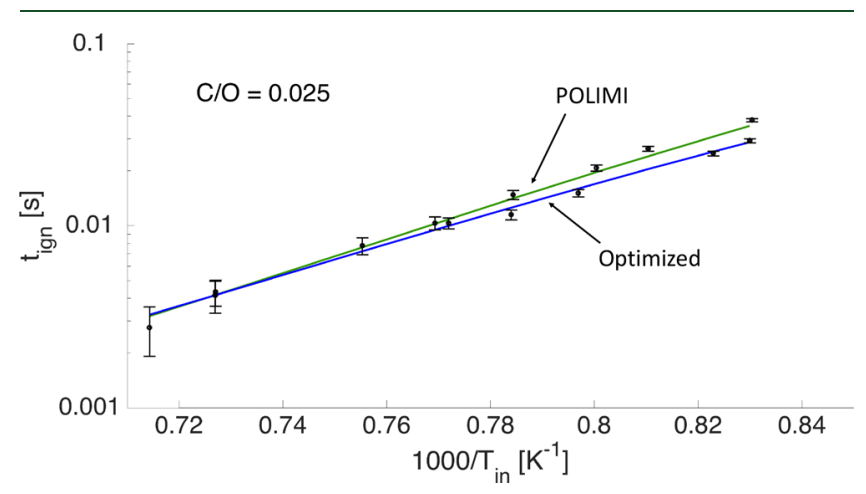

Figure 9. Comparison between the nominal (green) and optimized (blue) POLIMI $\mathrm{C} 1-\mathrm{C} 3^{30}$ mechanism for methane at $\mathrm{C} / \mathrm{O}=0.025$. 


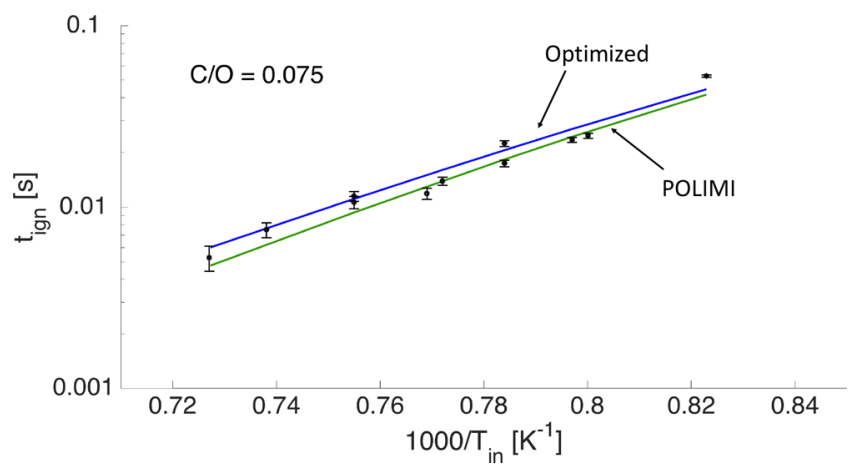

Figure 10. Comparison between the nominal (green) and optimized (blue) POLIMI $\mathrm{C} 1-\mathrm{C}^{30}$ mechanism for methane at $\mathrm{C} / \mathrm{O}=0.075$.

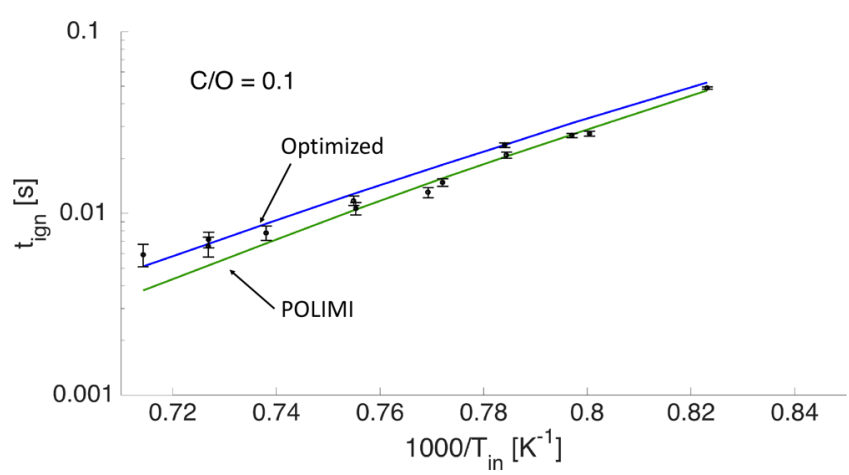

Figure 11. Comparison between the nominal (green) and optimized (blue) POLIMI $\mathrm{C} 1-\mathrm{C} 3^{30}$ mechanism for methane at $\mathrm{C} / \mathrm{O}=0.1$.

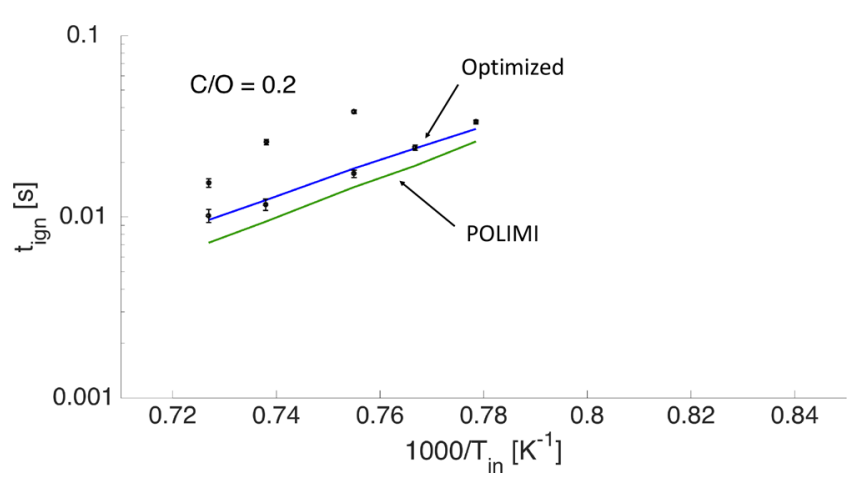

Figure 12. Comparison between the nominal (green) and optimized (blue) POLIMI $\mathrm{C} 1-\mathrm{C}^{30}$ mechanism for methane at $\mathrm{C} / \mathrm{O}=0.2$.

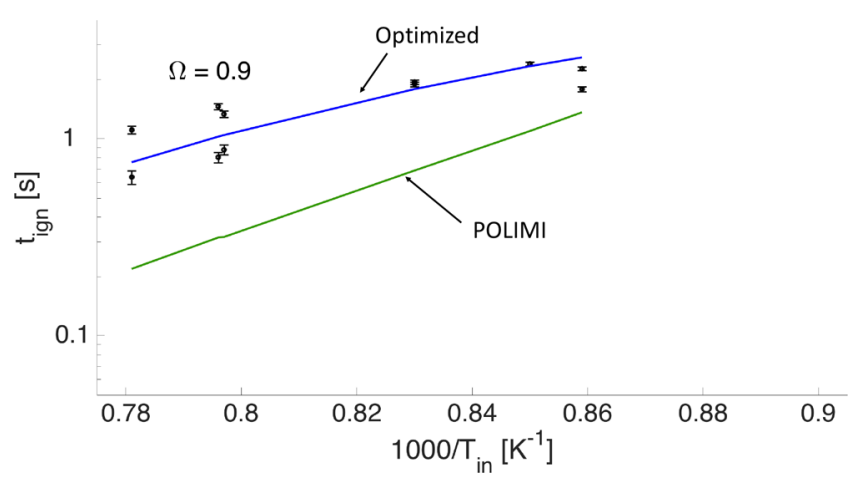

Figure 13. Comparison between the nominal (green) and optimized (blue) POLIMI $\mathrm{C} 1-\mathrm{C}^{30}$ mechanism for biomass pyrolysis products at $\Omega=0.9$.

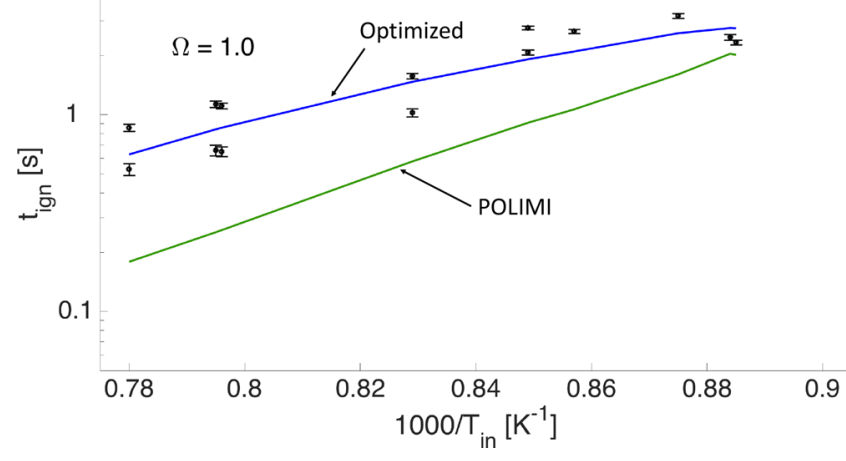

Figure 14. Comparison between the nominal (green) and optimized (blue) POLIMI $\mathrm{C} 1-\mathrm{C} 3^{30}$ mechanism for biomass pyrolysis products at $\Omega=1.0$.

Table 3. Resulting Parameter Combinations for Reactions $\mathrm{R} 1\left(\mathrm{O}_{2}+\mathrm{H}=\mathrm{O}+\mathrm{OH}\right), \mathrm{R} 271\left(\mathrm{HO}_{2}+\mathrm{CH}_{3}=\mathrm{OH}+\mathrm{CH}_{3} \mathrm{O}\right)$, and $\mathrm{R} 405\left(\mathrm{CH}_{4}+\mathrm{H}=\mathrm{H}_{2}+\mathrm{CH}_{3}\right)$ That for Each Evaluation Gave the Least Squared Error $S^{a}$

$\begin{array}{cll}\text { kinetic parameter } & \text { nominal value } & \text { optimized value } \\ A_{\mathrm{R} 1} & 9.6 \times 10^{11} & 6.1 \times 10^{11} \\ \beta_{\mathrm{R} 1} & -0.2 & -0.2 \\ E_{\mathrm{R} 1} & 16625 & 16556 \\ A_{\mathrm{R} 271} & 6.0 \times 10^{9} & 2.56 \times 10^{10} \\ A_{\mathrm{R} 405} & 3.0 \times 10^{4} & 7.54 \times 10^{4} \\ \beta_{\mathrm{R} 405} & 2 & 2 \\ E_{\mathrm{R} 405} & 10000 & 10139 \\ S & 2.03 \times 10^{-3} & 4.99 \times 10^{-4}\end{array}$

${ }^{a_{T}}$ The units of the different kinetic parameters are as follows: $A\left(\mathrm{~s} \mathrm{~cm}^{3}\right.$ $\mathrm{mol}), \beta$, and $E(\mathrm{cal} / \mathrm{mol})$.

To ensure that the performance of the optimized mechanism did not diminish for conventional conditions, a validation against the ignition delay time for methane in conventional conditions was also performed. This validation showed that the optimized mechanism gave improved predictions also for conventional conditions, with respect to the nominal POLIMI mechanism. This validation can be found in the Supporting Information.

\section{CONCLUSION}

Existing detailed chemical mechanisms are not accurate in predicting non-conventional combustion, such as MILD combustion. There is therefore a need to quantify and minimize the uncertainties in the mechanism with respect to these conditions. This work puts forth a methodology based on UQ of selected kinetic parameters chosen based on an impact factor ranking that gives major improvements in the prediction of the ignition delay time for MILD combustion. A new strategy for evaluating the physical limits of the kinetic parameters has also been developed within this work. The evaluation in this work was based on experimental data of the ignition delay time of methane and biomass pyrolysis products in MILD conditions in a PFR, extracted from Sabia et al. ${ }^{16}$ and Sabia et al. ${ }^{17}$

The three most impactful reactions were reactions $\mathrm{R} 1\left(\mathrm{O}_{2}+\right.$ $\mathrm{H}=\mathrm{O}+\mathrm{OH}), \mathrm{R} 271\left(\mathrm{HO}_{2}+\mathrm{CH}_{3}=\mathrm{OH}+\mathrm{CH}_{3} \mathrm{O}\right)$, and $\mathrm{R} 405$ $\left(\mathrm{CH}_{4}+\mathrm{H}=\mathrm{H}_{2}+\mathrm{CH}_{3}\right)$. The kinetic parameters from these three reactions were considered uncertain within their physical limits, and the following conclusions can be made based on 
results from the optimization process: (1) The parameter combination that gave the least squared fit, presented in Table 3, showed slight improvements for the methane cases, especially for high inlet temperatures and for the $\mathrm{C} / \mathrm{O}=0.2$ case, where the optimized mechanism showed improvements for all inlet temperatures. (2) For the biomass pyrolysis product cases, quite drastic improvements could be noticed, in both the slope and the ignition delay time predictions. (3) As seen in Table 3, the pre-exponential factor and activation energy for reaction $\mathrm{R} 1\left(\mathrm{O}_{2}+\mathrm{H}=\mathrm{O}+\mathrm{OH}\right)$ should be decreased slightly, while the temperature exponent should be kept the same value. (4) The pre-exponential factor for reaction $\mathrm{R} 271\left(\mathrm{HO}_{2}+\mathrm{CH}_{3}=\mathrm{OH}+\mathrm{CH}_{3} \mathrm{O}\right)$ should be increased by almost a factor of 2. (5) For reaction $\mathrm{R} 405\left(\mathrm{CH}_{4}\right.$ $\left.+\mathrm{H}=\mathrm{H}_{2}+\mathrm{CH}_{3}\right)$, the pre-exponential factor should be increased by a factor of 2.5 , while the temperature exponent should be kept to its nominal value and the activation energy should be reduced slightly. (6) Finally, a validation against the ignition delay time for methane-air mixtures in conventional conditions showed an improved performance also for these conditions.

The approach used in this paper has proven to be very successful on this set of data, and we plan to apply this methodology to a wider range of experimental targets, to confirm its potential. However, it should be noted that experimental data for MILD combustion in these kinds of systems, i.e., canonical reactors, are not so abundant. Moreover, the prediction of the ignition delay time is of major importance in MILD conditions; because it relies on a distributed ignition process, the use of these data as an initial step for the optimization based on MILD combustion was therefore warranted.

To further improve the mechanism, additional reactions could also be added to the optimization process. However, as seen in this work, using only these three reactions, quite significant improvements could be achieved. This work was therefore considered concluded, but in future work, the aspect of increasing the number of reactions will be evaluated to see if the performance could be improved further.

The aspect of combining mechanism reduction with UQ will also be explored in future work. This will make the mechanism applicable for large-scale simulations, and at the same time, the performance will be improved through the use of UQ.

\section{ASSOCIATED CONTENT}

\section{S Supporting Information}

The Supporting Information is available free of charge on the ACS Publications website at DOI: 10.1021/acs.energyfuels.8b01022.

Prior uncertainty range evaluation and validation against conventional conditions (PDF)

\section{AUTHOR INFORMATION}

\section{Corresponding Authors}

*E-mail: magnus.furst@ulb.ac.be.

*E-mail: alessandro.parente@ulb.ac.be.

\section{ORCID $\odot$}

Magnus Fürst: 0000-0003-1921-8635

Marco Lubrano Lavadera: 0000-0003-2173-4997

Alessio Frassoldati: 0000-0003-0264-438X

Alessandro Parente: 0000-0002-7260-7026

\section{Notes}

The authors declare no competing financial interest.

\section{ACKNOWLEDGMENTS}

This work has been carried out in the framework of the Short Term Scientific Mission Program of SMARTCATs COST Action (CM1404, www.smartcats.eu), supported by COST (European Cooperation in Science and Technology, www.cost. eu), and has received funding from the European Union's Horizon 2020 Research and Innovation Program under the Marie Skłodowska-Curie Grant Agreement 643134.

\section{REFERENCES}

(1) Cavaliere, A.; de Joannon, M. Prog. Energy Combust. Sci. 2004, 30, 329-366.

(2) Wang, F.; Mi, J.; Li, P. Energy Fuels 2013, 27, 3488-3498.

(3) Evans, M. J.; Medwell, P. R.; Wu, H.; Stagni, A.; Ihme, M. Proc. Combust. Inst. 2017, 36, 4297-4304.

(4) Tu, Y.; Yang, W.; Liu, H. Energy Fuels 2017, 31, 10144-10157.

(5) Sabia, P.; de Joannon, M.; Picarelli, A.; Chinnici, A.; Ragucci, R. Fuel 2012, 91, 238-245.

(6) Sabia, P.; Sorrentino, G.; Chinnici, A.; Cavaliere, A.; Ragucci, R. Energy Fuels 2015, 29, 1978-1986.

(7) Wang, H.; Sheen, D. A. Prog. Energy Combust. Sci. 2015, 47, 131.

(8) Smith, G. P.; Golden, D. M.; Frenklach, M.; Moriarty, N. W.; Eiteneer, B.; Goldenberg, M.; Bowman, C. T.; Hanson, R. K.; Song, S.; Gardiner, W. C. J.; Lissianski, V. V.; Qin, Z. GRI-Mech 3.0; http:// combustion.berkeley.edu/gri-mech/.

(9) Frenklach, M.; Packard, A.; Seiler, P. Prediction uncertainty from models and data. Proceedings of the 2002 American Control Conference (IEEE Catal. No.CH37301) 2002, 5, 4135-4140.

(10) You, X.; Packard, A.; Frenklach, M. Int. J. Chem. Kinet. 2012, 44, 101-116.

(11) Slavinskaya, N. A.; Abbasi, M.; Starcke, J. H.; Whitside, R.; Mirzayeva, A.; Riedel, U.; Li, W.; Oreluk, J.; Hegde, A.; Packard, A.; Frenklach, M.; Gerasimov, G.; Shatalov, O. Energy Fuels 2017, 31, 2274-2297.

(12) Varga, T.; Nagy, T.; Olm, C.; Zsély, I.; Pálvölgyi, R.; Valkó, É.; Vincze, G.; Cserháti, M.; Curran, H.; Turányi, T. Proc. Combust. Inst. 2015, 35, 589-596.

(13) Varga, T.; Olm, C.; Nagy, T.; Zsély, I. G.; Valkó, É.; Pálvölgyi, R.; Curran, H. J.; Turányi, T. Int. J. Chem. Kinet. 2016, 48, 407-422.

(14) Turányi, T.; Nagy, T.; Zsély, I. G.; Cserháti, M.; Varga, T.; Szabó, B. T.; Sedyó, I.; Kiss, P. T.; Zempléni, A.; Curran, H. J. Int. J. Chem. Kinet. 2012, 44, 284-302.

(15) Samu, V.; Varga, T.; Rahinov, I.; Cheskis, S.; Turányi, T. Fuel 2018, 212, 679-683.

(16) Sabia, P.; de Joannon, M.; Picarelli, A.; Ragucci, R. Combust. Flame 2013, 160, 47-55.

(17) Sabia, P.; Lubrano Lavadera, M.; Sorrentino, G.; Giudicianni, P.; Ragucci, R.; De Joannon, M. Flow, Turbul. Combust. 2016, 96, 433-448.

(18) Mueller, C. J.; Musculus, M. P. B.; Lyle, M.; Pitz, W. J.; Westbrook, C. K. Oxygen Ratio: A Fuel-Independent Measure of Mixture Stoichiometry; Lawrence Livermore National Laboratory: Livermore, CA, 2003.

(19) Cuoci, A.; Frassoldati, A.; Faravelli, T.; Ranzi, E. Combust. Flame 2013, 160, 870-886.

(20) Cuoci, A.; Frassoldati, A.; Faravelli, T.; Ranzi, E. Comput. Phys. Commun. 2015, 192, 237-264.

(21) Frenklach, M. Proc. Combust. Inst. 2007, 31, 125-140.

(22) Warnatz, J. Symp. Combust., [Proc.] 1992, 24, 553-579.

(23) Turányi, T.; Zalotai, L.; Dóbé, S.; Bérces, T. Phys. Chem. Chem. Phys. 2002, 4, 2568-2578.

(24) Cai, L.; Pitsch, H. Combust. Flame 2014, 161, 405-415.

(25) Cai, L.; Pitsch, H. Combust. Flame 2015, 162, 1623-1637. 
(26) Turányi, T.; Tomlin, A. S. Analysis of Kinetic Reaction Mechanisms; Springer: Berlin, Germany, 2014; p 355, DOI: 10.1007/978-3-662-44562-4.

(27) Zádor, J.; Zsély, I. G.; Turányi, T.; Ratto, M.; Tarantola, S.; Saltelli, A. J. Phys. Chem. A 2005, 109, 9795-9807.

(28) Baulch, D. L.; Bowman, C. T.; Cobos, C. J.; Cox, R. A.; Just, T.; Kerr, J. A.; Pilling, M. J.; Stocker, D.; Troe, J.; Tsang, W.; Walker, R. W.; Warnatz, J. J. Phys. Chem. Ref. Data 2005, 34, 757-1397.

(29) Manion, J. A.; Huie, R. E.; Levin, R. D.; Burgess, D. R., Jr.; Orkin, V. L.; Tsang, W.; McGivern, W. S.; Hudgens, J. W.; Knyazev, V. D.; Atkinson, D. B.; Chai, E.; Tereza, A. M.; Lin, C.-Y.; Allison, T. C.; Mallard, W. G.; Westley, F.; Herron, J. T.; Hampson, R. F.; Frizzell, D. H. NIST Chemical Kinetics Database; National Institute of Standards and Technology (NIST): Gaithersburg, MD, 2015; http:// kinetics.nist.gov/.

(30) Ranzi, E.; Frassoldati, A.; Grana, R.; Cuoci, A.; Faravelli, T.; Kelley, A. P.; Law, C. K. Prog. Energy Combust. Sci. 2012, 38, 468501.

(31) Nagy, T.; Valkó, É.; Sedyó, I.; Zsély, I. G.; Pilling, M. J.; Turányi, T. Combust. Flame 2015, 162, 2059-2076.

(32) Couckuyt, I.; Forrester, A.; Gorissen, D.; De Turck, F.; Dhaene, T. Advances in Engineering Software 2012, 49, 1-13.

(33) Couckuyt, I.; Dhaene, T.; Demeester, P. J. Mach. Learn. Res. 2014, 15, 3183-3186.

(34) Rasmussen, C. E.; Williams, C. K. I. In Gaussian Processes for Machine Learning; Dietterich, T., Bishop, C., Heckerman, D., Jordan, M., Kearns, M., Eds.; The MIT Press: Cambridge, MA, 2004; pp 69106.

(35) Sheen, D. A.; You, X.; Wang, H.; Løvås, T. Proc. Combust. Inst. 2009, 32, 535-542.

(36) Zhang, Y.; Sahinidis, N. V. Ind. Eng. Chem. Res. 2013, 52, 3121-3132.

(37) Prager, J.; Najm, H. N.; Sargsyan, K.; Safta, C.; Pitz, W. J. Combust. Flame 2013, 160, 1583-1593.

(38) Metcalfe, W. K.; Burke, S. M.; Ahmed, S. S.; Curran, H. J. Int. J. Chem. Kinet. 2013, 45, 638-675.

(39) Zhou, C.-W.; Li, Y.; O'Connor, E.; Somers, K. P.; Thion, S.; Keesee, C.; Mathieu, O.; Petersen, E. L.; DeVerter, T. A.; Oehlschlaeger, M. A.; Kukkadapu, G.; Sung, C.-J.; Alrefae, M.; Khaled, F.; Farooq, A.; Dirrenberger, P.; Glaude, P.-A.; Battin-Leclerc, F.; Santner, J.; Ju, Y.; Held, T.; Haas, F. M.; Dryer, F. L.; Curran, H. J. Combust. Flame 2016, 167, 353-379.

(40) Healy, D.; Kalitan, D. M.; Aul, C. J.; Petersen, E. L.; Bourque, G.; Curran, H. J. Energy Fuels 2010, 24, 1521-1528.

(41) Bowman, C.; Hanson, R.; Davidson, D.; Gardiner, W. J.; Lissianski, V.; Smith, G.; Golden, D.; Frenklach, M.; Goldenberg, M. GRI-Mech 2.11; http://www.me.berkeley.edu/gri_mech/.

(42) Chemical-Kinetic Mechanisms for Combustion Applications; http://web.eng.ucsd.edu/mae/groups/combustion/mechanism.html.

(43) Zhukov, V. P. Proceedings of the 4th European Conference for Aerospace Sciences (EUCASS); Saint Petersburg, Russia, July 4-8, 2011; 2012. 